\title{
DEFESA NACIONAL E A SOCIEDADE BRASILEIRA: A IMPORTÂNCIA DA CONSCIENTIZAÇÃO
}

\section{ARTIGO ORIGINAL}

CRUZ, Wagner Jorge de Paula ${ }^{1}$

JUNIOR, Adival José Reinert ${ }^{2}$

CRUZ, Wagner Jorge de Paula. JUNIOR, Adival José Reinert. Defesa Nacional e a Sociedade Brasileira: A importância da conscientização. Revista Científica Multidisciplinar Núcleo do Conhecimento. Ano 05, Ed. 06, Vol. 13, pp. 15-29. Junho de 2020. ISSN: 2448-0959, Link de acesso: https://www.nucleodoconhecimento.com.br/ciencias-sociais/importancia-daconscientizacao

\section{RESUMO}

O presente artigo propõe uma discussão sobre a utilidade das Forças Armadas para o país. Baseia-se na constatação do baixo nível de informação e de circulação na sociedade brasileira à respeito do tema Defesa Nacional e da importância que a mesma exerce sobre a vida do cidadão. O objetivo da pesquisa foi o de abordar a necessidade de se falar sobre o assunto em todas as esferas da sociedade, especificamente naquelas onde o ensino, a saúde, a segurança e a infraestrutura chegam de forma muito precária, visto que o Brasil, apesar de figurar entre as dez maiores economias do mundo, segundo o seu Produto Interno Bruto (PIB), possui má distribuição de renda e há desigualdades sociais que prejudicam o seu

\footnotetext{
${ }^{1}$ Pós-graduado em Engenharia de Automação e Eletrônica Industrial, e graduado em Engenharia de Controle e Automação.

${ }^{2}$ Especialização em Teoria Psicanalítica. Especialização em Orientação, Supervisão e Gestão Escolar Democrática. Especialização em Docência do Ensino Fundamental, Médio e Superior. Graduação em Matemática.
} 
desenvolvimento, tendo uma população pobre, em sua maioria, a qual possui dificuldades de leitura, de interpretação e de entendimento. Pretendeu-se fazer uma síntese sobre as Forças Armadas do Brasil, destacando a origem, o desenvolvimento e sua função conforme a legislação, visando, também, promover um questionamento sobre o orçamento de Defesa, comparando, para tanto, os investimentos de alguns países do mundo, considerando, nesse processo, a geopolítica e os recursos humanos e materiais que nosso país possui. Por fim, chegou-se à conclusão de que para fazer uma Estratégia Nacional de Defesa, deve-se elaborar políticas públicas de acordo com o assunto, eficiência e eficácia, visando a transparência nos assuntos de Defesa, pois, a Política de Defesa, deve responder aos interesses da sociedade e do Estado, havendo, com isso, uma nação coesa em ideias e objetivos para o futuro do país. Para isso, deverá ter maior envolvimento e conscientização em assuntos ligados à Defesa Nacional, tendo o direito e o dever de pautar debates sobre o tema, já que as decisões de paz e de guerra também dizem respeito à soberania popular. Este estudo teve como metodologia de pesquisa a revisão de artigos e documentos.

Palavras-chave: Forças Armadas, Defesa Nacional, geopolítica, Base Industrial de Defesa, sociedade.

\section{INTRODUÇÃO}

Este artigo traz um breve histórico das Forças Armadas no Brasil, abordando temas como a Segurança Nacional, a Defesa Nacional, a Geopolítica do Brasil e a Base Industrial de Defesa, de forma simples e objetiva, para que uma pessoa leiga no assunto entenda e tenha uma visão mais ampla sobre sua importância e a de seu país no cenário mundial. Foram realizadas pesquisas em sites institucionais, em site de plataforma de vídeos, em documentos constitucionais e em artigos referentes ao tema, que constam na bibliografia. Foi abordado o assunto de Defesa Nacional, demonstrando a necessidade da mudança de pensamento, da falta de infraestrutura e de investimentos destinados ao orçamento de Defesa e ao uso inteligente e sério, visando o aumento do poder dissuasório do país para manter sua soberania, contribuindo com a pacificação entre os demais países do mundo. Por último, foi 
apresentado o pensamento de que só será possível melhorar a sociedade brasileira a partir de uma educação que promova a consciência nacional, segurança e saúde melhores, gerando qualidade de vida ao cidadão.

\section{DEFESA NACIONAL E A SOCIEDADE BRASILEIRA: A IMPORTÂNCIA DA CONSCIENTIZAÇÃO}

\subsection{FORÇAS ARMADAS}

Atualmente, como previsto na Constituição Federal de 1988, no Art. 142, as Forças Armadas desempenham funções fundamentais na defesa do país.

\subsection{HISTÓRICO DAS FORÇAS ARMADAS}

As Forças Armadas tiveram sua origem no Brasil colonial, cenário em que ocorreram conflitos e rebeliões civis, os quais foram suprimidos pelas Forças Nacionais que defendiam o território brasileiro. Por meio da Constituição de 1824, Dom Pedro I, imperador, deu início à organização das forças militares brasileiras (Marinha e Exército). Segundo Aguiar (1986), as Forças Armadas pretendidas pela Constituição de 1824 não eram permanentes, eram obedientes ao poder, destinavam-se à manter uma ordem política que surgiu na independência, além de funções de Defesa externa e interna do país. Em 1891, o texto constitucional apresentou uma nova visão para as Forças Armadas, estabelecendo, em seu Art. 14, que estas eram instituições nacionais, permanentes, destinadas à defesa da Pátria no exterior e à manter as leis no interior do país, obrigadas à sustentar as instituições constitucionais, sendo obedientes aos superiores hierárquicos.

Em 1934, o tema Defesa Nacional foi apresentado constitucionalmente pela primeira vez no Art. 142, que aludia que as Forcas Armadas eram instituições nacionais permanentes e obedientes aos seus superiores hierárquicos, dentro da lei, também destinadas à defender a Pátria e garantir os Poderes constitucionais. As Forças Armadas Nacionais tiveram grande utilidade nos conflitos externos, nas revoltas 
internas e na política, tendo representação na Presidência da República ao longo do tempo. Também foram necessárias à implantação do regime militar (ditadura militar), em 1964, o qual lutava contra rebeldes que buscavam estabelecer, no Brasil, outro regime (a ditadura do proletariado), que era baseado e sustentado por ideias e valores comunistas iniciados na antiga União Soviética (URSS[3]), pois o mundo estava dividido entre os Estados Unidos da América (capitalismo) e a União Soviética (socialismo).

Isto acarretou diversas mortes de ambos os lados, causando, na população, até os dias de hoje, uma aversão aos militares, pois somente uma parte da história foi disseminada no Brasil, parte essa que diz respeito aos excessos cometidos pelos militares na época, sendo que os rebeldes também cometeram seus excessos e a chamada ditadura do proletariado ainda é pouco discutida, atualmente. Porém, voltando à cronologia da história, observou-se que a Constituição de 1937 fez referência em três títulos às Forças Armadas, demonstrando a importância que os militares tiveram naquele período. Terminada a II Guerra Mundial, diversos países reformularam e promulgaram novas constituições, inclusive o Brasil, elaborando a Constituição de 1946, que buscava uma redemocratização. A Constituição de 1946 estabeleceu um limite para a atuação do Presidente da República na utilização das Forças Armadas, as quais ganharam mais autonomia institucional.

Estabelece-se o seguinte: são instituições nacionais permanentes, organizadas com base na hierarquia e na disciplina tendo como autoridade suprema o Presidente da República, destinadas a defender a Pátria e garantir os poderes constitucionais, a lei e a ordem. Ao longo do tempo, o uso das Forças Armadas na proteção do país tem sido discutido e atualizado por diferentes Constituições no que se refere à sua utilização e autonomia. Pois bem, ficam subordinadas ao Presidente da República, estabelecendo uma estreita ligação entre o regime presidencialista e o papel desempenhado pelas Forças Armadas no país, ou seja, quanto mais autoritário o presidente for, poderá usar as Forças Armadas para reprimir o povo, ferindo a democracia, como visto atualmente, em países de governos com filosofia socialista, por exemplo: Cuba, Coréia do Norte, China e Venezuela, que desarmaram sua 
população, aparelharam o Estado e as Instituições, ditando regimes não democráticos.

Então, isso nos leva a pensar que cada povo possui o líder que merece, pois ele é apenas o reflexo de sua sociedade, logo, o brasileiro deve ser mais politizado e conscientizado nacional e internacionalmente sobre os reais interesses do país para entender suas potencialidades e suas fraquezas perante outros países. As fraquezas são ameaças à soberania nacional e segundo o general Luiz Eduardo Rocha Paiva[4], doutor em Aplicações, Planejamento e Estudos Militares:

As "potências democráticas do Eixo do Poder" desenvolveram poder global e nível de vida e bem-estar das suas sociedades muito elevado e têm como aspiração manter aquele status. Uma ameaça real e concreta para um país emergente e rico em recursos como o nosso. (...) Como exemplo dessa "projeção de poder", o general Luiz Eduardo Rocha Paiva cita o fato de já existir, no âmbito da Organização das Nações Unidas, a Resolução 1.674, de 2006, cujo objetivo foi resumido na expressão "responsabilidade de proteger". Com o aval da ONU e sob o amplo guarda-chuva da "proteção de civis em conflitos armados", tais potências podem implementar intervenção internacional sobre uma nação, evocando qualquer um desses motivos: direitos humanos, questões ambientais, questões sociais e ilícitos - transnacionais. (...) "Essas 'grandes causas' não raro estão associadas a interesses econômicos, haja vista que o genocídio em Ruanda não mereceu atenção (já a invasão do Kuwait, por conta do petróleo, mereceu)", escreveu o almirante, em artigo publicado na revista Interesse Nacional (FERREIRA; BARROS, 2016, p. 13).

Observa-se, então, que a Segurança Nacional deve ser uma garantia constitucional aos cidadãos para promover a manutenção da segurança externa e interna de um país. Após o regime militar e a promulgação da Constituição de 1988, as Forças Armadas foram reorganizadas constitucionalmente, conforme o Art. 142[5]: 
Art. 142. As Forças Armadas, constituídas pela Marinha, pelo Exército e pela Aeronáutica, são instituições nacionais permanentes e regulares, organizadas com base na hierarquia e na disciplina, sob a autoridade suprema do Presidente da República, e destinam-se à defesa da Pátria, à garantia dos poderes constitucionais e, por iniciativa de qualquer destes, da lei e da ordem.

$\S 1^{\circ}$ - Lei complementar estabelecerá as normas gerais a serem adotadas na organização, no preparo e no emprego das Forças Armadas (CONSTITUIÇÃO, 1988).

Deste modo, as Forças Armadas estão subordinadas ao Presidente da República, dentro dos limites da lei e cumprimento de suas funções constitucionais, conforme os artigos 142 e 143[6], da Carta Magna[7].

\subsection{SEGURANÇA NACIONAL E DEFESA NACIONAL}

Conforme Gonçalves[8] e Rudzit[9] (2012 apud FERREIRA; BARROS, 2016), a Segurança Nacional abrange uma Segurança Pública referente aos crimes comuns praticados em território nacional, logo, o conceito de Defesa Nacional se ocupa de ameaças externas. Assim, cabe, aos órgãos institucionais, como a polícia federal; a rodoviária; a ferroviária; a penal; a civil; a militar e aos corpos de bombeiros militares estabelecerem a Segurança Pública a partir do seu correto funcionamento, diminuindo os níveis de criminalidade, de acidentes, de desastres, entre outras funções, ficando à cargo das Forças Armadas o controle sobre as fronteiras, o preparo e o adestramento para a proteção do seu território, do seu patrimônio e de seus cidadãos. Mas, apesar das Forças Armadas cumprirem com sua destinação constitucional, também Ihes cabem atribuições subsidiárias que estão explicitadas na Lei Complementar no 97/99[10]. Em seu Art. 15, a Lei Complementar no 97/1999 estabelece o emprego das Forças Armadas, observe:

$\S 2^{\circ}$ A atuação das Forças Armadas, na garantia da lei e da ordem, por iniciativa de quaisquer dos poderes constitucionais, ocorrerá (...), após 
esgotados os instrumentos destinados à preservação da ordem pública e da incolumidade das pessoas e do patrimônio, relacionados no art. 144 da Constituição Federal.

$\S 3^{0}$ Consideram-se esgotados os instrumentos (...) quando, em determinado momento, forem eles formalmente reconhecidos pelo respectivo Chefe do Poder Executivo Federal ou Estadual como indisponíveis, inexistentes ou insuficientes ao desempenho regular de sua missão constitucional. (Incluído pela Lei Complementar ํำ 117, 2004).

$\S 4$ ํㅡ $\mathrm{Na}$ hipótese de emprego nas condições previstas no § 30 deste artigo, após mensagem do Presidente da República, serão ativados os órgãos operacionais das Forças Armadas, que desenvolverão, de forma episódica, em área previamente estabelecida e por tempo limitado, as ações de caráter preventivo e repressivo necessárias para assegurar o resultado das operações na garantia da lei e da ordem (Incluído pela Lei Complementar № 117, 2004) (LC 97/1999).

Segundo o general Silveira (2017), a Defesa Nacional, na visão do Exército brasileiro, seria o conjunto de ações do Estado, com ênfase na expressão militar para proteger o território, a soberania e os interesses nacionais contra ameaças externas e que as Forças Armadas são essencialmente e não exclusivamente os instrumentos de Defesa do Estado brasileiro, não deixando de apoiar os órgãos institucionais que são voltados para a segurança pública. Além do mais, o Brasil possui uma vertente preventiva da Defesa que é baseada na valorização da ação diplomática para a solução de conflitos por meio da existência de uma estrutura militar com credibilidade e que seja capaz de gerar efeito dissuasório. Conforme diz a Política Nacional de Defesa (PND) (2016, p. 15), a "Defesa Nacional é o conjunto de medidas e ações do Estado, com ênfase no campo militar, para a defesa do território, da soberania e dos interesses nacionais contra ameaças preponderantemente externas, potenciais ou manifestas". 
E, diante das mudanças no cenário mundial, a definição de Defesa Nacional sofre modificações ao longo do tempo, pois o tema apresenta complexidade por conta dos diversos elementos a serem analisados para obter compreensão. Segundo Amorim (2013), a Defesa Nacional possui um contexto muito mais amplo na visão do Estado de Direito Democrático, não se tratando apenas da atuação de forças armadas regulares no combate à potenciais ameaças ou perigos externos como, também, à ameaças internas ao modelo político-social, considerando, nesse processo, a interpretação jurídico-social que leva em conta o conjunto de responsabilidades que o poder público apresenta na resolução de conflitos e tensões que variam de intensidade e determinam ou influenciam a vulnerabilidade do país, desde relações com outras nações à problemas sociais internos decorrentes de antagonismos na própria sociedade.

\subsection{A GEOPOLÍTICA NO BRASIL}

Quando se ouve falar em Geopolítica, as pessoas logo pensam que se trata de um assunto que envolve apenas Geografia e Política, porém ele tem uma abordagem muito mais ampla. Grande parte da sociedade brasileira não tem o conhecimento sobre a importância do território; da sobrevivência; dos recursos naturais; financeiros; das fronteiras e, principalmente da Defesa. Foi observado, ao longo do tempo, que relações de poder e de defesa são geradas sempre que um grupo social se apropria de um espaço para viver e, conforme Costa (1992), as relações territoriais não implicam, necessariamente, na ausência de um sistema político formal, pois há sempre uma estrutura de domínio. Com os avanços da tecnologia que possibilitaram, atualmente, a quarta revolução industrial, a globalização ganhou força e as relações entre os países se tornaram mais intensas, porém mais complexas, pois há uma interdependência entre eles.

Nesse sentido, cabe auferir que o conceito de Geopolítica também incorporou elementos cibernéticos, nucleares e espaciais gerando, dessa forma, novas agendas (interesses). Com isso, o homem ganhou mais poder, porém a velocidade de seu desenvolvimento é a mesma que o leva à destruição. O poder está intimamente ligado 
ao seu uso, ou melhor, em saber usá-lo. Segundo Weigert (1944), os países possuem a Geopolítica que merecem ou que aspiram. O pensamento geopolítico envolve a observação e a melhoria das limitações e das potencialidades de um país com base numa consciência de defesa e de bem-estar social da população. Conforme Moraes (1996), Geopolítica e interesse nacional começam com a:

Formulação de uma política verdadeiramente nacional, que reflita as necessidades e interesses dos diferentes estratos da sociedade civil. $O$ fundamento há de ser a consciência do que corresponde aos interesses nacionais permanentes da nação: a sobrevivência nacional, a integridade territorial, a independência, a autodeterminação e a segurança nacionais, o bem-estar da população, a defesa da identidade cultural, a preservação dos valores nacionais, etc. [...] nesse campo, possam surgir eventualmente discrepâncias e divergências fundamentais (Emb. Lauro Escorel de Moraes, 1986).

Segundo Castro (1986), o Brasil está entre as nações mais populosas do mundo e existem três condições essenciais para que uma nação se torne uma grande potência: o espaço, a posição e as matérias-primas. Isto nos coloca em evidência dentro do conceito geopolítico global, no entanto o Brasil ainda não se tornou uma grande potência, pois, conforme Couto e Silva (1981), não haverá Geopolítica brasileira sem que se considere o Brasil como o centro do universo e, nas palavras de Jaguaribe (2002), preservar a autonomia do Brasil é fundamental para que o país tenha um destino próprio. Vale ressaltar a importância do atlântico sul que é considerada a Amazônia azul do Brasil por causa do petróleo descoberto no pré-sal. Nossa floresta amazônica conta com riquezas e uma ampla biodiversidade e o continente antártico nos possibilita pesquisas principalmente referentes ao clima e o continente sulamericano que segundo Mattos (1977), promove peso político e econômico no comércio internacional, facilitando o desenvolvimento de todos os seus países.

Ao aproveitar as estruturas regionais já existentes, demandaria, num primeiro passo, integrar o MERCOSUL[11] ao Pacto Andino[12], realizando o velho sonho de todos, 
de terem acesso comercial aos mercados do Atlântico e do Pacífico (MATTOS, 1977). A ideia de aumentar a interligação entre os países da América do Sul e de ligar os dois oceanos Pacífico e Atlântico por meio do continente demanda estratégia de infraestrutura. O Brasil é um país continental, tem o potencial de melhorar o setor industrial, a educação, a inclusão social e a redistribuição de renda dentro do país e no continente. Ao se ter essa visão de progresso, precisa-se buscar uma ordem, tanto estratégica e estrutural nas contas públicas quanto nos valores éticos e morais.

Só assim o país terá dinheiro para fazer investimentos e uma população consciente para saber onde, o quê, como e o porquê de se investir em Defesa Nacional (Forcas Armadas), educação, cultura, saúde e infraestrutura, promovendo o suporte para o desenvolvimento sustentável pautado na coesão nacional, levando em consideração que a sociedade brasileira é resultado do encontro de populações de origens geográficas e étnicas diversificadas, o que resultou em uma população miscigenada.

Muitos especialistas denunciam a ausência de um projeto nacional de desenvolvimento a guiar as escolhas e prioridades da esfera pública e buscar a convergência de esforços com a iniciativa privada. Somente um amplo debate nacional poderia indicar essa estratégia [...] Para a construção de estratégias de longo prazo, é necessário pactuar essa estratégia entre os diversos atores envolvidos, monitorar e avaliar as decisões tomadas vis-à-vis as mudanças no ambiente, para que essas estratégias não sofram solução de continuidade ao longo do tempo. Sem uma estratégia de longo prazo pactuada, o Brasil continuará a mercê da estratégia de outros (IPEA, 2017).

Visando a transparência nos assuntos de Defesa para com as cidadãs e cidadãos brasileiros foi elaborado um documento denominado de Livro Branco de Defesa Nacional[13] (LBDN) que permite conhecer as ações do Estado nesta área. A Política de Defesa responde aos interesses da sociedade e do Estado, observe: 
O Brasil é uma República Federativa que adota o presidencialismo como sistema de governo. A divisão de Poderes - Executivo Legislativo e Judiciário - é, no ordenamento jurídico brasileiro, um princípio fundamental e necessário à promoção do bem da coletividade. Por esta razão, a divisão se baseia no equilíbrio entre os três Poderes e em sua colaboração e controle recíprocos e conscientes (Livro Branco de Defesa Nacional, 2012, p. 16).

O Brasil, à luz dos princípios constitucionais que regem suas relações internacionais, pauta-se pela participação proativa nas negociações que envolvem os temas de desarmamento, não proliferação e controle de armas. A partir das inquestionáveis necessidades de segurança ditadas pelo cenário político-estratégico de defesa, entende que medidas realistas e críveis de redução ou eliminação de armamentos e processos transparentes de verificação podem vir a ser adotados multilateralmente, propiciando ambiente de confiança mútua entre Estados soberanos (Livro Branco de Defesa Nacional, 2012, p. 40).

Vale ressaltar a fala da chefe do executivo (presidente), publicada no Livro Branco de Defesa Nacional em 2012, aludia que tinha-se como prioridade de governo acabar com a pobreza extrema no Brasil e que as Forças Armadas, com sua larga experiência em trabalhos sociais desenvolvidos em todo o território nacional, possuía valor inestimável na busca desse objetivo. Vários projetos e programas sociais foram desenvolvidos juntamente com o Ministério da Defesa e com as Forças Armadas visando a socialização e a segurança dos cidadãos. Projetos e programas como: Projeto Soldado Cidadão; Programa Calha Norte; Programa Forças no Esporte e Projeto Rondon podem ser destacados. Sem contar as ações subsidiárias e constitucionais em benefício da sociedade, alguns exemplos como: a fiscalização das fronteiras para evitar a propagação de doenças; campanhas de vacinação e combate e prevenção à Dengue e apoio aos Direitos Humanos no Haiti. 
Porém, desde 2012, o Brasil vem sofrendo com a desaceleração da economia devido ao aumento dos gastos públicos, causando cortes nos orçamentos e principalmente no orçamento da Defesa, pois o modelo econômico baseado no consumo se tornou insustentável, já que, ao longo do tempo, o país não produziu riquezas nem tão pouco fez reformas importantes para o seu desenvolvimento. A realidade atual contrasta com o discurso político daqueles que passaram pelo cargo de chefe do executivo nos últimos 28 anos, desde 1990. Segundo o Ministério do Planejamento Orçamento e Gestão[14] (MPOG), as maiores consequências da falta de responsabilidade fiscal nas contas públicas do governo brasileiro se deu a partir de 2015, pois o Ministério da Defesa teve o 5 maior corte orçamentário no valor de: $\mathrm{R} \$ 696,7$ milhões, ocasionando impactos diretos em despesas como investimentos, passagens e diárias, que são consideradas despesas não obrigatórias.

\subsection{BASE INDUSTRIAL DE DEFESA (BID)}

De acordo com o Ministério da Defesa[15] (2020), Base Industrial de Defesa (BID) é o conjunto de empresas estatais ou privadas com participação em uma ou mais etapas de pesquisa, desenvolvimento, produção, distribuição e manutenção de produtos estratégicos de Defesa, bens e serviços que contribuem para a Segurança ou para a Defesa do país. O Estado define o tamanho e a propriedade de sua Indústria de Defesa, pois o governo é o principal comprador e não segue as leis tradicionais de oferta e demanda de mercado. Com isso, detém o monopólio do consumidor (Monopsônio), além de fornecer subsídios, determinar as compras preferenciais e controlar os lucros.

Possui demanda influenciada por fatores estratégicos e políticos, sendo uma indústria estratégica e que em nenhuma hipótese poderá ser de controle estrangeiro, ao passo que necessita do desenvolvimento tecnológico; científico; mão de obra especializada entre outras coisas, ou seja, depende diretamente do orçamento. Conforme dados do Stockholm International Peace Research Institute (SIPRI), na Figura 1 e 2 são apresentados alguns orçamentos de defesa de países do mundo, até o ano de 2016, em relação ao Produto Interno Bruto (PIB) dos respectivos países, veja: 
Figura 1 - Porcentagem do PIB destinada ao orçamento de Defesa dos respectivos países

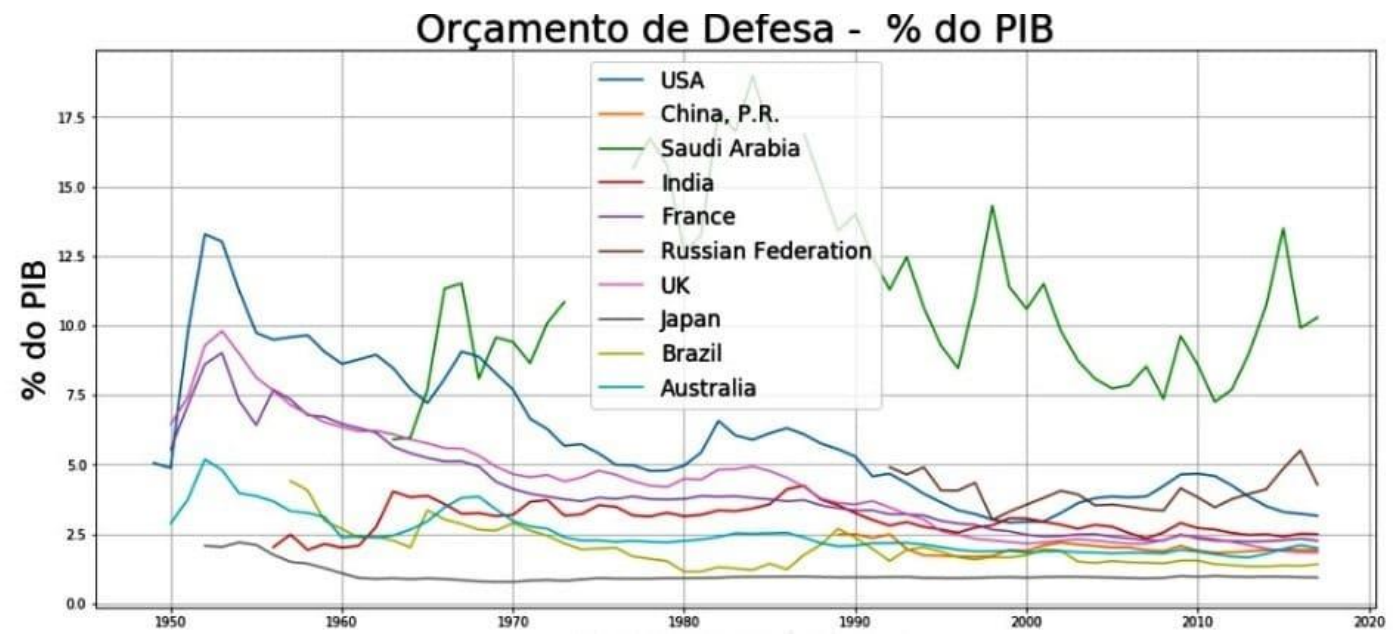

Fonte: https://www.sipri.org/

Note que o Brasil figura entre os menores investimentos no setor e que os Estados Unidos da América, ao longo do tempo, destina grande distribuição dos recursos para a Defesa. Agora, observe a Figura 2 a seguir:

Figura 2 - Orçamento de Defesa dos países da América do Sul

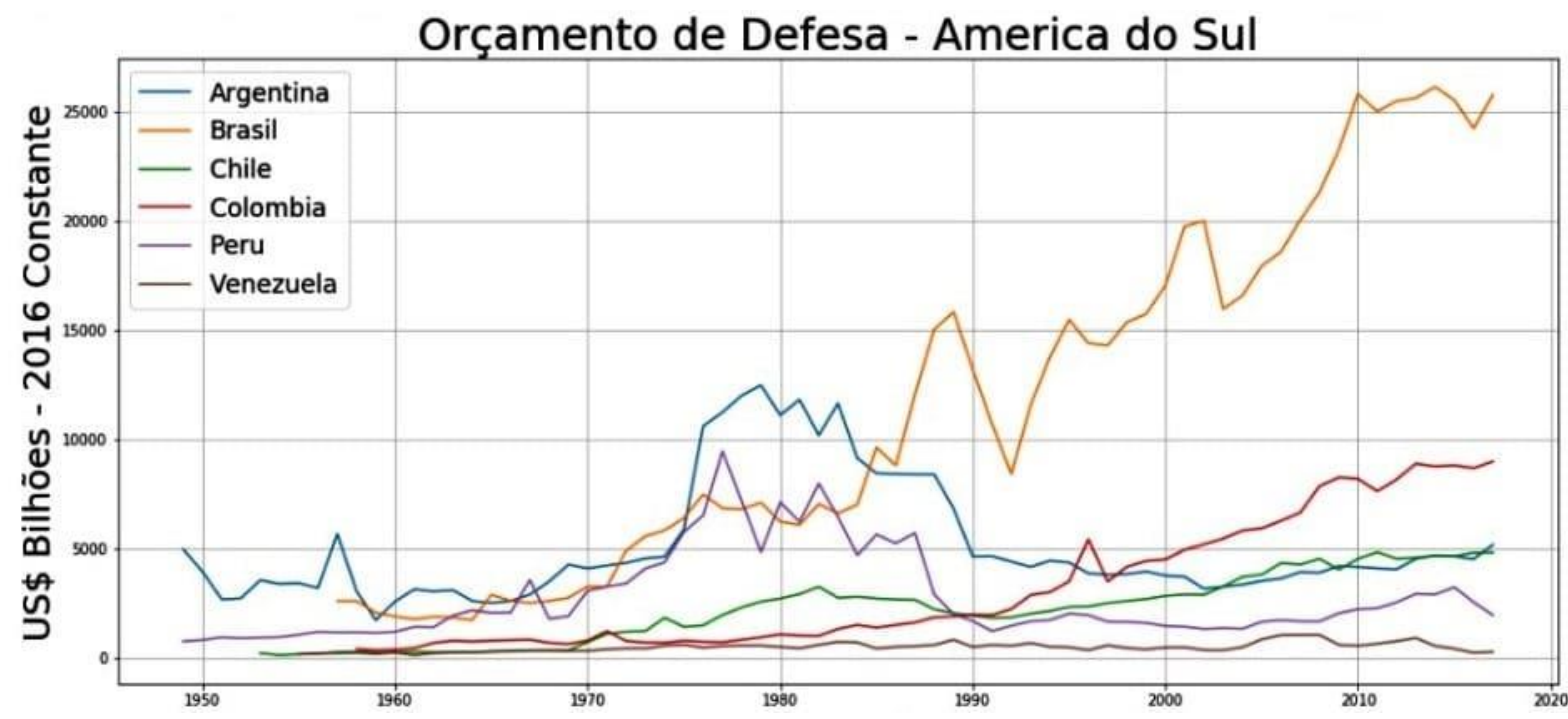

Fonte: https://www.sipri.org/

Disponível em: https://www.nucleodoconhecimento.com.br/ciencias-sociais/importancia-daconscientizacao 
Nota-se que investimos mais em defesa do que nossos países vizinhos, mas o fato de só direcionar dinheiro para este setor não implica em desenvolvimento e uso correto dos recursos. A América do Sul é considerada, no mundo, como uma área pacífica, logo, investir em defesa mais do que os países vizinhos seria pressuposto para um mal-estar. Portanto, é necessário que o Brasil se desenvolva baseado na confiança mútua, estabelecendo, assim, a segurança regional.

\section{CONSIDERAÇÕES FINAIS}

Conclui-se que para aumentar a capacidade de produção da Indústria de Defesa certas medidas devem ser tomadas, já que o desenvolvimento econômico e tecnológico de um país está diretamente ligado a Indústria de Defesa. Por isso. É preciso investir em educação, desde a base, nas escolas e colégios, até as universidades e centros de formação, fomentando, então, profissionais capacitados para atuar em diversas áreas da sociedade brasileira e principalmente na Defesa, criando infraestrutura e qualidade de vida para essa mão de obra qualificada que terá o dever moral de contribuir para o desenvolvimento do Brasil, evitando perdê-los para o mercado estrangeiro, pois adquirir tecnologia de ponta e encontrar especialistas nacionais que trabalham com as mesmas é uma tarefa difícil por consequência do baixo índice de investimentos na Defesa comparado a outros países.

O abismo tecnológico entre o Brasil e os demais países precisa ser diminuído para que tenha maior poder de dissuasão. O domínio de tecnologias sensíveis de forma autônoma está inerente a todo país que visa promover pesquisa e desenvolvimento nos setores estratégicos como o espacial, o cibernético e o nuclear, reforçando os pilares da Política Nacional de Defesa (PND). Logo, a criação e a revisão do Livro Branco de Defesa Nacional e de outros documentos legais como Políticas Públicas ligadas à Defesa são de suma importância para o país, pois contribuem para o entendimento entre a sociedade e suas lideranças civis conscientizando os brasileiros sobre o serviço militar, a modernização das Forças Armadas, a ética e a moral, ou seja, haverá uma coesão nacional baseada no diálogo entre os diversos setores da 
sociedade brasileira construindo no presente o seu futuro. Defesa Nacional é projeto de Estado e não de governo.

\section{REFERÊNCIAS}

AGUIAR, R. A. R. de. Os militares e a constituinte: poder civil e poder militar na constituição. São Paulo: Alfa-Omega, 1986.

AMORIM, A. P. de. Novos Paradigmas para a Defesa e a Segurança Nacionais. Revista de Informação Legislativa. 2013. Disponível em: https://www2.senado.leg.br/bdsf/bitstream/handle/id/502934/000991761.pdf?sequen ce $=1$ \&isAllowed $=y$. Acesso em: 10 mar. 2020.

AMORIM, A. P. de. Novos Paradigmas para a Defesa e a Segurança Nacionais. Revista de Informação Legislativa, Ano 50, n. 200, out./dez. 2013.

BRASIL. Câmara dos Deputados. Relações Exteriores e Defesa Nacional - Papel das Forças Armadas. Brasília. 2019. Disponível em: https://www.youtube.com/watch?v=1pND4W0VwK0. Acesso em: 05 mar. 2020.

BRASIL. Constituição (1988). Constituição da República Federativa do Brasil. Brasília. 1988.

Disponível em: http://www.planalto.gov.br/ccivil_03/constituicao/constituicao.htm. Acesso em: 26 fev. 2020.

BRASIL. Ministério da Defesa. A Indústria de Defesa Brasileira: Situação Atual e Perspectivas de evolução. Congresso Acadêmico sobre Defesa Nacional. Disponível em: https://www.defesa.gov.br/arquivos/ensino_e_pesquisa/defesa_academia/cadn/artig os/palestras/3_a_industria_de_defesa_brasileira_situacao_atual_e_perspectivas_de evolucao.pdf. Acesso em: 11 mar. 2020. 
BRASIL. Ministério da Defesa. Base Industrial de Defesa. Brasília. 2016. Disponível em: https://www.defesa.gov.br/industria-de-defesa/base-industrial-de defesa. Acesso em: 26 fev. 2020.

BRASIL. Ministério da Defesa. Estratégia Nacional de Defesa. Brasília. 2016. Disponível em: https://www.defesa.gov.br/estado-e-defesa/estrategia-nacional-de defesa. Acesso em: 24 fev. 2020.

BRASIL. Ministério da Defesa. Livro Branco de Defesa Nacional. Brasília. 2016. Disponível em: https://www.defesa.gov.br/estado-e-defesa/livro-branco-de-defesa nacional. Acesso em: 24 fev. 2020.

BRASIL. Ministério da Defesa. Política Nacional de Defesa. Brasília: Senado. 2016. Disponível em: https://www.defesa.gov.br/estado-e-defesa/politica-nacional-de defesa. Acesso em: 24 fev. 2020.

BRASIL. Ministério da Defesa. Projetos Estratégicos. Brasília. 2016. Disponível em: https://www.defesa.gov.br/index.php/industria-de-defesa/paed/projetos-estrategicos. Acesso em: 24 mar. 2020.

CASTRO, T. de. Retrato do Brasil: Atlas-texto de Geopolítica. Rio de Janeiro: BIBLIEx, 1986.

COSTA, W. M. Geografia política e geopolítica. Discursos sobre o território e poder. São Paulo: Editora HUCITEC, 1992.

COUTO E SILVA, G. Geopolítica do Brasil. Livraria José Olympio Editora. Rio de Janeiro, 1981

FELIPE, C. L. O Brasil e a sua Base Industrial de Defesa (BID): Situação Atual e Perspectivas de Direção. 2019. Disponível em: https://www.defesa.gov.br/arquivos/ensino_e_pesquisa/defesa_academia/cedn/xxi_c edn/10_o_brasil_e_sua_base_industrial_de_defesa.pdf. Acesso em: 25 mar. 2020. 
FERREIRA; P. A; BARROS, R. B. B. O papel das Forças Armadas na Defesa Nacional. 2016.

Disponível em:

https://www.defesa.gov.br/arquivos/ensino_e_pesquisa/defesa_academia/cadn/artig os/XIIIcadn/o_papel_das_foras_armadas_na_defesa_nacional.pdf. Acesso em: 10 mar. 2020.

FERREIRA; P. A; BARROS, R.B.B. O papel das Forças Armadas na Defesa Nacional. 2016. 22f. Artigo (Bacharel em Direito) - Universidade de Uberaba, Uberaba, 2016.

GONZALES, M. S. L. de. M. Geopolítica do Brasil: possibilidades, limitações e sua relação com a Defesa. Escola Naval, RJ. 2019. Disponível em: https://www.defesa.gov.br/arquivos/ensino_e_pesquisa/defesa_academia/cadn/artig os/palestras/2_geopolitica_do_brasil_possibilidades_limitaes_e_sua_relao_com_a_d efesa.pdf. Acesso em: 25 mar. 2020.

JAGUARIBE, H. A reconfiguração da ordem mundial no início do século XXI. Brasília: Câmara dos Deputados, Comissão de Relações Samuel Pinheiro Guimarães e de Defesa Nacional, 2002.

MATTOS, M. A Geopolítica e as Projeções do Poder. Rio de Janeiro: Livraria José Olympio Editora, 1977.

SILVA, M. L. et al. A Construção da Imagem Pacifista do Brasil e as Suas Consequências no Desenvolvimento Militar do País. Academia da Força Aérea. Pirassununga. 2017. Disponível em: https://www.defesa.gov.br/arquivos/ensino_e_pesquisa/defesa_academia/cadn/artig os/xiv_cadn/a_construao_da_imagem_pacifista_do_brasil_e_as_suas_consequenci as_no_desenvolvimento_militar_do_pais.pdf. Acesso em: 10 mar. 2020.

SILVEIRA, G. R. M. da. Segurança e Defesa: A visão do Exército Brasileiro. 2017. Disponível em: http://afaportugal.org/index.php/2017/01/14/seguranca-e-defesa-avisao-do-exercito-brasileiro/. Acesso em: 20 fev. 2020. 
WEIGERT, H. W. Geopolítica: generales y geógrafos. México, DF: Fondo de Cultura Economica, 1944.

\section{APÊNDICE - REFERÊNCIAS DE NOTA DE RODAPÉ}

\section{União das Repúblicas Socialistas Soviéticas.}

4. O General de brigada Luiz Eduardo Rocha Paiva (Exército Brasileiro R1) possui Doutorado em Aplicações, Planejamento e Estudos Militares na Escola de Comando e Estado-Maior do Exército (ECEME), Mestrado em Aplicações Militares na Escola de Aperfeiçoamento de Oficiais e Pós Graduação Lato Sensu em Política, Estratégia e Alta Administração Militar - Especialização, com ênfase em Estratégia, na ECEME e Pós-Graduação Lato Sensu MBA Executivo do Exército Brasileiro - Especialização, na FGV - RJ - 2000.

5. Art. 142. As Forças Armadas, constituídas pela Marinha, pelo Exército e pela Aeronáutica, são instituições nacionais permanentes e regulares, organizadas com base na hierarquia e na disciplina, sob a autoridade suprema do Presidente da República, e destinam-se à defesa da Pátria, à garantia dos poderes constitucionais e, por iniciativa de qualquer destes, da lei e da ordem.

$\S 1^{\circ}$ Lei complementar estabelecerá as normas gerais a serem adotadas na organização, no preparo e no emprego das Forças Armadas.

$\S$ 2ํNão caberá habeas corpus em relação a punições disciplinares militares.

$\S 3^{\circ}$ Os membros das Forças Armadas são denominados militares, aplicando-Ihes, além das que vierem a serem fixadas em lei, as seguintes disposições: (Incluído pela Emenda Constitucional no 18, de 1998);

I - as patentes, com prerrogativas, direitos e deveres a elas inerentes, são conferidas pelo Presidente da República e asseguradas em plenitude aos oficiais da ativa, da reserva ou reformados, sendo-Ihes privativos os títulos e postos militares e, 
juntamente com os demais membros, o uso dos uniformes das Forças Armadas; (Incluído pela Emenda Constitucional no 18, de 1998);

II - o militar em atividade que tomar posse em cargo ou emprego público civil permanente, ressalvada a hipótese prevista no art. 37, inciso XVI, alínea "c", será transferido para a reserva, nos termos da lei; (Redação dada pela Emenda Constitucional no 77, de 2014);

III - o militar da ativa que, de acordo com a lei, tomar posse em cargo, emprego ou função pública civil temporária, não eletiva, ainda que da administração indireta, ressalvada a hipótese prevista no art. 37, inciso XVI, alínea "c", ficará agregado ao respectivo quadro e somente poderá, enquanto permanecer nessa situação, ser promovido por antiguidade, contando-Ihe o tempo de serviço apenas para aquela promoção e transferência para a reserva, sendo depois de dois anos de afastamento, contínuos ou não, transferido para a reserva, nos termos da lei; (Redação dada pela Emenda Constitucional no 77, de 2014);

IV - ao militar são proibidas a sindicalização e a greve; (Incluído pela Emenda Constitucional no 18, de 1998);

V - o militar, enquanto em serviço ativo, não pode estar filiado a partidos políticos; (Incluído pela Emenda Constitucional no 18, de 1998);

$\mathrm{VI}$ - o oficial só perderá o posto e a patente se for julgado indigno do oficialato ou com ele incompatível, por decisão de tribunal militar de caráter permanente, em tempo de paz, ou de tribunal especial, em tempo de guerra; (Incluído pela Emenda Constitucional no 18, de 1998);

VII - o oficial condenado na justiça comum ou militar a pena privativa de liberdade superior a dois anos, por sentença transitada em julgado, será submetido ao julgamento previsto no inciso anterior; (Incluído pela Emenda Constitucional nำ18, de 1998); 
VIII - aplica-se aos militares o disposto no art. $7^{\circ}$, incisos VIII, XII, XVII, XVIII, XIX e XXV e no art. 37, incisos XI, XIII, XIV e XV; (Incluído pela Emenda Constitucional no 18, de 1998); VIII - aplica-se aos militares o disposto no art. 7º, incisos VIII, XII, XVII, XVIII, XIX e XXV, e no art. 37, incisos XI, XIII, XIV e XV, bem como, na forma da lei e com prevalência da atividade militar, no art. 37, inciso XVI, alínea "c"; (Redação dada pela Emenda Constitucional oㅜ 77, de 2014);

6. Art. 143. O serviço militar é obrigatório nos termos da lei.

$\S 1^{\circ}$ Às Forças Armadas compete, na forma da lei, atribuir serviço alternativo aos que, em tempo de paz, após alistados, alegarem imperativo de consciência, entendendose como tal o decorrente de crença religiosa e de convicção filosófica ou política, para se eximirem de atividades de caráter essencialmente militar. (Regulamento)

$\S 2^{\circ}$ - As mulheres e os eclesiásticos ficam isentos do serviço militar obrigatório em tempo de paz, sujeitos, porém, a outros encargos que a lei lhes atribuir. (Regulamento) (Constituição Federal de 1988).

7. A carta magna garantia aos nobres um comando mais justo por parte da realeza. Ela foi criada na Inglaterra, em 1215. Apesar de os reis estarem em uma posição superior a todas as classes no período, eles precisavam manter o controle da população e ter o apoio de parte dela, principalmente os que tinham acesso à informação e armamento. Sendo assim, o documento tinha objetivo de servir como uma "balança" entre os diferentes interesses da realeza e dos nobres, um acordo para que o rei não cometesse tantas injustiças. O Brasil também tem uma carta magna, a constituição de 1988, essa é a mais atualizada. Também conhecida como constituição cidadã, ela é a décima do mundo em previsão de direitos. De acordo com o CPP (Comparative Constitutions Project), a carta magna brasileira soma atualmente 79 direitos.

8. Consultor do Senado Joanisval Brito Gonçalves, 2012. 
9. Professor Gunther Rudzit, coordenador do Curso de Relações Internacionais da Fundação Armando Álvares Penteado (FAAP), de São Paulo, 2012.

10. LCP 97/1999 (lei complementar) 09/06/19; LCP 117 de 02/09/2004: altera os arts. $13,15,16,17$ e 18 e acresce arts 17-a e 18-a. LCP 136, de 25/08/2010: altera os arts. $2^{\circ}, 4^{\circ}, 7^{\circ}, 9^{\circ}, 11,12,15$ e 18; acresce os arts. 3-a, 11-a e 16-a; revoga o art. 10 e o inciso iv do art. 17-a.

11. Com mais de duas décadas de existência, o Mercado Comum do Sul (MERCOSUL) é a mais abrangente iniciativa de integração regional da América Latina, surgida no contexto da redemocratização e reaproximação dos países da região ao final da década de 80 .

12. Em 26 de maio de 1969, pelo Acordo de Cartagena, Colômbia, Peru, Venezuela, Equador, Bolívia e Chile criaram uma União Aduaneira e Econômica para fazer restrições à entrada de capital estrangeiro, com base em estudos da Comissão Econômica para a América Latina (CEPAL), órgão da ONU.

13. O Livro Branco de Defesa Nacional (LBDN) é o mais completo e acabado documento acerca das atividades de defesa do Brasil. Abrangente, visa esclarecer a sociedade brasileira e a comunidade internacional sobre as políticas e ações que norteiam os procedimentos de segurança e proteção à nossa soberania.

14. O Ministério do Planejamento (MP) foi um ministério do Poder Executivo do Brasil. Sua função era planejar a administração governamental, planejar custos, analisar a viabilidade de projetos, controlar orçamentos, liberar fundos para estados e projetos do governo. A Medida Provisória ํo 870, de 1ํ de janeiro de 2019, criou o Ministério da Economia. Com isso, as estruturas dos ministérios da Fazenda; do Planejamento, Desenvolvimento e Gestão; da Indústria, Comércio Exterior e Serviços; e do Trabalho passaram a integrar um novo ministério chamado Economia. Desde então, o conteúdo de notícias e a agenda de autoridades públicas encontram-se disponíveis e atualizados no Portal da Economia em: https://www.gov.br/economia/pt-br. 
15. O Ministério da Defesa (MD) é o órgão do Governo Federal incumbido de exercer a direção superior das Forças Armadas, constituídas pela Marinha, pelo Exército e pela Aeronáutica. Uma de suas principais tarefas é o estabelecimento de políticas ligadas à Defesa e à Segurança do País, caso da Política de Defesa Nacional (PDN), atualizada em julho de 2005. Criado em 10 de junho de 1999, o MD é o principal articulador de ações que envolvam mais de uma Força Singular.

Enviado: Maio, 2020.

Aprovado: Junho, 2020. 